Wales is proud of its successes, and reflects on areas where it can improve provision. This session will provide a overview of the DSW corporate plan (2009-2013), focusing on the developing participant/performer pathway and the pivotal role that education is playing through the process of up-skilling and training key mainstream partners, as the nation drives towards a more inclusive delivery system. The presenters will draw upon their experiences of building their disability sport development model, the critical decisions that have been taken and the tools that have been developed to support the process during the last 10 years.

\section{DISABILITY SPORT WALES PROGRAMME: MAKING THE CONNECTIONS}

Jon Morgan, ${ }^{1}$ Fiona Reid ${ }^{1}$ Executive Director, Disability Sport Wales, Sport Wales, Sophia Gardens, Cardiff, UK; '2Education and Training Manager, Disability Sport Wales, Sport Wales, Sophia Gardens, Cardiff, UK

\subsection{6/bjsm.2010.078725.255}

Wales is a principality of 2.9 million people which is divided into 22 local authorities. Disability Sport Wales (DSW) has been part of the sporting landscape of Wales since 1995, and now combines provision and development of community, academy and performance level sport, underpinned by appropriate education and training support. In 2002, Wales offered 1200 community participation opportunities a year, rising to 600000 by 2009; talented athletes are fed into the DSW Academy which launched in 2006 and has so far provided services to 80 emerging athletes; at the Beijing 2008 Paralympic Games Wales contributed 31 of the 212 athletes to Team GB. 